\title{
Apresentação \\ O Sistema Galperin-Talízina na Didática Desenvolvimental: Elementos iniciais de uma contextualização
}

Isauro Beltrán Núñez

Gloria Fariñas León

Betânia Leite Ramalho

A Obutchénie, Revista de Didática e Psicologia Pedagógica, apresenta neste número um conjunto de textos dedicados ao Sistema Galperin-Talízina com o intuito de contribuir com as discussões que se desenvolvem no Brasil sobre a Didática Desenvolvimental, um dos focos das preocupações da revista.

Uma apresentação desses autores, como representantes da Escola Soviética da Psicologia, exige um compromisso científico e profissional, embora breve, e uma análise histórica e lógica de como se configura o pensamento desses teóricos num dado sistema didático com um potencial significativo e atual para as práticas pedagógicas na escola do século XXI.

\section{Situando o Sistema Galperin-Talízina}

Como explicam Núñez e Oliveira (2015), após a Grande Revolução Socialista de Outubro de 1917, na antiga Rússia, com a constituição da URSS, a Psicologia Soviética passou a ser parte de um projeto de importância social. Sendo assim, foi necessária uma reestruturação criativa da Psicologia Soviética (uma verdadeira revolução) a partir das críticas à Psicologia tradicional, à qual se aplicou de forma inovadora as ideias do materialismo dialético como fundamento filosófico dessa nova proposta. Foi uma necessidade não apenas teórica, mas também prática alimentada pelo compromisso com os desafios das transformações da sociedade. 
Essas mudanças estão associadas a L. S. Vygotski e a um grupo de seus colegas e colaboradores. O ano de 1924, se destaca como um momento marcante dos estudos da Psicologia de base marxista, no grupo da Universidade de Moscou conhecido como "tróika", do qual faziam parte Vygotski, A. N. Leontiev e A. R. Lúria preocupados por conferir à Psicologia um caráter científico fundamentado no materialismo dialético e definir seu objeto de estudo como ciência, assim como desenvolver métodos adequados a seu caráter de ciência. Esses estudiosos formularam algumas perguntas relevantes como foco de suas preocupações científicas relacionadas com a compreensão da origem da psique humana e a essência de seu desenvolvimento dos fenômenos, dentre outras. Pode-se dizer que esse grupo, liderado por Vygotski estabeleceu as leis fundamentais do desenvolvimento da personalidade ao elaborar os fundamentos de uma concepção histórico-culturalista na Psicologia.

Posteriormente, dadas determinadas circunstâncias históricas do país, estabeleceu-se o grupo ou escola de Kharkov, capital da Ucrânia no período entre 1919 e 1934. A história desse movimento começou no final de 1931 ou início de 1932, quando um grupo de jovens psicólogos dentre os discípulos mais próximos de Vygotski em Moscou (A. N. Leontiev, A. V. Zaporozhets, L. I. Bozhovich e T. O. Ginevskaya) partiu para essa cidade com o objetivo de continuar as pesquisas na concepção histórico-culturalista sob a liderança de A.N. Leontiev. A esse grupo inicial, logo se juntaram vários pesquisadores, entre eles, P. Ya. Galperin, P. I. Zinchenko, V. I. Asnin, G. D. Lukov e K. E. Khomenko.

As ideias em Kharkov eram heterogêneas, mas unidas pelas mesmas preocupações de estudo. Como em todo verdadeiro grupo de cientistas, as contradições entre seus membros favoreceram a elaboração de diferentes pontos de vistas teóricos que se integravam e se negavam de forma dialética.

Em Kharkov, Leontiev realizou, nos anos de 1930-1940, numerosos estudos experimentais preocupados com a discussão do papel da atividade individual e da atividade prática no desenvolvimento do psiquismo humano, o que levou à formulação de suas ideias sobre a Teoria da Atividade, reconhecida na Psicologia soviética como um paradigma teórico geral. Não obstante, entendemos que a Teoria 
da Atividade de Leontiev, mais do que um ponto de vista alternativo da Teoria Histórico-Cultural, se constituiu como uma continuação dialética, ao se integrar e considerar as teses fundamentais e ideias-chave da concepção histórico-culturalista como as de mediação, internalização, controle das funções mentais, dentre outras, o que evidencia, segundo Leontiev, D. (2005), o fato de Leontiev nunca ter refutado, negado ou contrariado os fundamentos básicos da Teoria Histórico-Cultural de Vygotski. Das múltiplas possibilidades da Teoria Histórico Cultural, Leontiev escolheu e desenvolveu, de acordo com as exigências histórico-políticas, ideológicas como também científicas da época, a atividade da relação atividade-comunicação estabelecida por Vigotski, dando status de teoria a esse desenvolvimento.

Esses foram marcos da elaboração teórica relevante da escola da Psicologia soviética, pautada em um esforço sistemático para mudar todos os seus fundamentos, possibilitando definir seu objeto de estudo e avançar no entendimento científico da origem e desenvolvimento do psiquismo humano, nos quais categorias, como atividade, consciência e personalidade, se tornariam estruturantes do novo pensamento psicológico soviético.

A concepção histórico-culturalista é um sistema aberto para pensar a realidade do desenvolvimento humano com o fundamento de leis, princípios, categorias ou conceitos e metodologias válidos como generalidade. No entanto, são ajustáveis a condições culturais e históricas específicas, sem perder a validez pois uma das características fundamentais da abordagem teórico-metodológica vygotskiana é sua clareza na visão da unidade complexa e dialética entre o geral e o particular. O ser humano é concebido como único e enraizado na cultura e no tempo em que vive, mas é orientado para o futuro em sua construção criativa e, também, histórica e cultural.

No eixo das preocupações da concepção histórico-culturalista tomou força, dentre outras, as discussões sobre a problemática da aprendizagem nas relações dialéticas com o desenvolvimento, especialmente a aprendizagem organizada no contexto escolar.

Nesse momento histórico surgem, por conseguinte, diferentes abordagens teóricas e metodológicas que podem ser caracterizadas como sistemas didáticos 
com certas peculiaridades. No entendimento de Longarezi (2018), podem ser identificados três sistemas didáticos que compartilham pressupostos da Teoria Histórico-Cultural de Vygotski quais sejam: Sistema Zankov, Sistema GalperinTalízina e Sistema Elkonin-Davidov-Repkin. Esses sistemas, de forma regular, têm sido apresentados em diferentes edições desta revista por seus valores científicos respectivos e porque expressam a riqueza de interpretações geradas pela teoria de Vygotski, assim como pelas contribuições de muitos de seus seguidores, dentre eles Leontiev.

Em relação à compreensão do Sistema Galperin-Talízina, apresentado neste Dossiê, se faz necessário explicitar algumas ideias de como se configura seu marco teórico, destacando a Teoria da Formação Planejada das Ações Mentais e dos Conceitos de Galperin, assim como as contribuições de N. F. Talízina no campo da Didática Desenvolvimental.

\section{P. Ya. Galperin e sua Teoria da Formação Planejada das Ações Mentais e dos Conceitos}

Piotr Yakovlevich Galperin (1902-1988), foi um eminente psicólogo soviético e cientista emérito da República Socialista Federativa Soviética Russa (RSFSR). Discípulo e colaborador de Vygotski se formou em Medicina na Universidade de Kharkov. Mais tarde, se transferiu para o Departamento de Psicologia da Academia de Psiconeurologia desta cidade, onde realizou vários trabalhos em conjunto com A. N. Leontiev, A. R. Luria e A. V. Zaporozhetz. Sob a liderança de Leontiev, participa de forma ativa na formulação da Teoria da Atividade desse teórico, articulada aos fundamentos da Teoria Histórico Cultural de Vygotski. Em 1936, completou seu trabalho de candidatura a doutor intitulado "Diferenças psicológicas entre o uso de instrumentos por animais e pelo homem". Em 1945, na Universidade Estadual Mikhail Lomonosov, em Moscou, iniciou suas atividades como professor e pesquisador interessado nos problemas teóricos da Psicologia e ciências afins como também nos problemas do desenvolvimento infantil, no qual trabalhou até sua morte. Nessa universidade, chefiou o Laboratório de 
Desenvolvimento Ontogenético. Foi professor no Departamento de Psicologia Geral e Aplicada, assim como Diretor da Cátedra de Psicologia das Idades, dentre outros.

$\mathrm{Na}$ Universidade de Moscou, teve uma intensa e frutífera vida acadêmica. Participou em diferentes eventos nacionais e internacionais de importância, nos quais apresentou e debateu com cientistas reconhecidos suas ideias científicas, como na Sociedade de Psicólogos da URSS e no XV Congresso Internacional de Psicologia Aplicada.

Galperin desenvolveu uma metodologia criativa, considerada como Psicologia Genética Geral, onde se revela a essência por trás dos fenômenos do desenvolvimento mental em condições de uma educação respeitosa das leis descobertas pelos pesquisadores histórico-culturalistas e analisadas criticamente, em contraste com as abordagens psicológicas - ainda atuais - fundamentalmente baseadas na formação espontânea, não direcionada e não controlada, das funções mentais (processos). O cientista criou o que hoje é conhecido como a Teoria da Formação Planejada das Ações Mentais e dos Conceitos, bem como um conjunto de outras proposições teóricas, que conferem ao mesmo um caráter de programa de pesquisa (NÚÑ̃Z, 2009).

Talvez menos conhecido por alguns leitores, mas verdadeiramente relevante para o desenvolvimento da Psicologia e suas relações com outras ciências (visão interdisciplinar), foi seu estudo crítico sobre a evolução histórica do objeto de estudo da Psicologia e sua redefinição, muito de acordo com aquela chamada por Vygotski de Nova Psicologia. Essa proposta destaca a natureza orientadora da atividade psíquica em seus diferentes níveis de organização, o que é consistente com seus estudos sobre as características da atividade de orientação e seu papel na qualidade do desenvolvimento do sujeito como personalidade. Seu trabalho sobre o desaparecimento dos instintos humanos também é menos conhecido, mas é notável por sua vigência.

Tudo isso diz respeito do alcance do pensamento de Galperin, além da teoria que o identifica mundialmente. Da mesma forma, diz respeito à diversidade e amplitude de seus interesses científicos de manifesto em suas investigações teóricas e metodológicas que visaram aprofundar e desenvolver a Psicologia e sua 
interdisciplinaridade. Uma particularidade muito valiosa da teoria de Galperin tem sido seu valor imediato, que não significa dizer mecânico, para a prática de uma educação voltada para o desenvolvimento da personalidade dos estudantes.

Sua teoria sobre a formação planejada de ações mentais e de conceitos assume significativa relevância à luz das demandas urgentes da escola do século XXI. Ensinar os alunos a aprender de forma abrangente, a se orientar conscientemente na atividade de estudo, possibilita o desenvolvimento de suas habilidades para aprender a aprender, para ser reflexivo e crítico, pois eles são os principais protagonistas de suas aprendizagens na busca de seu desenvolvimento integral. Permite uma aprendizagem situada e contextualizada na qual os alunos podem dar sentido a seus aprendizados em diálogo com o conteúdo científico da escola, que os ajuda a pensar, agir e a se desenvolver como personalidades críticas.

\section{Análise geral da teoria de Galperin}

Como se sabe, uma teoria é pertinente se sua abordagem, de alguma forma, guiar a prática e se puder fornecer boas soluções para os problemas da realidade, próprios de seu objeto de estudo, o que está posto por excelência na teoria de Galperin. Não entanto, a relação entre as duas dimensões (teoria e prática) deve ser cuidadosamente observada, uma vez que, aqui, não há como copiar e colar. Assumir uma relação reprodutiva como essa limita o potencial prático de qualquer proposta teórica. Por sua vez, mesmo as teorias que foram exaustivamente demonstradas, como a de Galperin, não significa que estejam completas e finalizadas.

A realidade viva é muito mais rica que sua conceitualização onde uma não corresponde ponto a ponto à outra. A pergunta é válida para qualquer proposta teórica. E Nos campos da educação e do desenvolvimento humano essa interpretação corre o risco de sofrer formulações inadequadas, por exemplo, ao se tentar ajustar a diversidade e a singularidade humana, centros de nossa consideração, a esquemas abstratos, em detrimento do desenvolvimento criativo de cada um dos atores da atividade acadêmica. Para Zinchenko (1990), o sujeito não internaliza o alheio, mas sim o próprio, e isso o sujeito precisa criar. 
A pretensão da teoria de Galperin a torna duplamente viável. Primeiro, para compreender e explicar os fenômenos e processos que ocorrem durante a formação do plano mental e sua inter-relação dialética com os planos verbais e práticos da atividade de aprendizagem. Segundo, para orientar o ensino na Zona de Desenvolvimento Próximo (ZDP). O ensino nas escolas, em geral, de certa maneira omitiu o papel das regularidades do desenvolvimento descobertas pela concepção histórico-culturalista na concepção e na instrumentação didática da aprendizagem. No entanto, ainda persiste o interesse de muitos pesquisadores mundo afora pelo entendimento e aplicação da teoria de Galperin.

Uma questão crítica para entender essa e outras teorias como a de Galperin pode estar não na própria teoria, mas em sua leitura, uma vez que existem visões que tendem a limitar ou distorcer sua abordagem e sua aplicação. A conscientização desse problema é fundamental para o leitor, pois em teorias como essa, que se referem à condição humana ou à educação, as implicações devem ser levadas em consideração, não apenas as implicações ontológicas e as epistemológicas, mas também as éticas e as políticas. O enriquecimento da relação teoria-prática resulta de sua boa interpretação, enquanto uma compreensão incorreta pode determinar alguns erros e descrédito. A apropriação de uma teoria por parte de pesquisadores ou professores deve recriar essa relação de acordo com a realidade concreta da aplicação, sem algoritmos a serem seguidos, sem que se torne um estereótipo ou um dogma. Além disso, sem assumi-la ad libitum, pois é necessário garantir rigor em todas as análises, nada em desacordo com a dinâmica criativa, por isso também deve-se ser crítico e responsável, e não apenas caprichoso (FARIÑAS, 2015).

Os leitores da Teoria Histórico-Cultural em geral, e da teoria de Galperin em particular, são heterogêneos. Existem muitos leitores que simplificam o conteúdo lido para adaptá-lo ao seu esquema de referência habitual como é o caso dos positivistas. Eles buscam, então, relações lineares e associativas, não a história e a complexidade do conteúdo na leitura e muito menos assumem a teoria de forma crítica e criativa. Os modelos positivista e instrumentalista têm estado presentes no pensamento científico por longos anos e sobreviveram até 
hoje à teoria marxista - sua contrapartida por excelência- em muitos campos do conhecimento científico, incluindo a Psicologia e a Pedagogia. Portanto, não surpreende que, na interpretação de um enfoque dialético e complexo da natureza como o histórico-culturalista, possa haver leitores que concebam as relações internas dos processos do desenvolvimento como associações externas como faz o behaviorismo mesmo em suas versões menos ortodoxas. As práticas derivadas dessas interpretações são geralmente mecanicistas e abstratas. Ao mesmo tempo, esse ponto de vista dá grande espaço ao pragmatismo, portanto, à aspiração de haver um algoritmo útil (ou receita) e, em outros casos, uma panaceia para a solução de problemas de ensino e aprendizagem na escola.

Outro tipo de leitor conhece o papel da compreensão literal de um texto, no entanto, transcende o que é afirmado. Compreende seu sentido e pode analisar criticamente o que é dito, procurando nichos de indagação ou enriquecimento teórico-prático, atitude mais propensa à busca de relações não mecânicas no que foi estudado (FARIÑAS, 2017 e 2019). Esse leitor, mesmo sem ser marxista, tem possibilidades de compreender a complexidade dialética das coisas. Diferentemente, os leitores da visão positivista tendem a perder de vista as unidades dialéticas de interpretação que conferem ao texto um caráter geral, complexo e aberto.

A busca por uma educação eminentemente eficiente, baseada na teoria de Galperin (uma atitude correspondente às abordagens positivistas) é um sinal de seu mal-entendido, porque essa perspectiva teórica respeita cada ser humano como um sujeito singular que pode aprender e se desenvolver em seu próprio ritmo peculiar, cumprindo certas características psicológicas do desenvolvimento (parâmetros, para este autor), como, por exemplo, racionalidade, generalização, criticidade, autonomia, entre outros. Essas características surgirão de acordo com os processos alcançados pelo sujeito do desenvolvimento, sem a exigência de padrões de resultados a serem atendidos. A relação entre aprendizagem e desenvolvimento deve ser entendida como interna e histórica (zona de desenvolvimento próximo), não associativa. Portanto, não pode ser manipulada direta e linearmente. Diferentemente do positivismo, para esse enfoque, mais (conhecimentos e habilidades, por exemplo) não significa melhor (aprendizado ou 
desenvolvimento). Não é o professor, mas o aluno que cria e recria seu desenvolvimento nas condições educacionais organizadas pelo primeiro. A tentativa de encontrar uma panaceia para a educação nesta ou em outras teorias é basicamente ingênua do ponto de vista científico e político.

O estudo dos três subsistemas que compõem a Teoria da Formação Planejada de Ações Mentais e de Conceitos mostra o caráter interdependente entre a história da humanidade - filogenética e ontogenética (Galperin, 1979) - e a constituição dos diferentes planos hierárquicos da psique no desenvolvimento. Significa uma recusa ao seu entendimento como uma simples adição de três condições. É necessário esclarecer como a leitura simplificada ou mecânica dos referidos subsistemas leva a uma visão simplificada da zona de desenvolvimento próximo. Além disso, devemos destacar como sua visão complexa e dialética nos permite entender e explicar os acontecimentos e avanços que-nela ocorrem.

De forma geral, cada subsistema, e todos em conjunto, fornecem fundamentos essenciais para observar com cuidado, mas também de maneira aberta e flexível, a dinâmica da zona de desenvolvimento próximo, ao mesmo tempo em que os fundamentos nela intervêm. Se, em lugar de examinar a lista de subsistemas, os víssemos em sua estrutura interdependente, poderíamos, pelo menos, entender e explicar:

A ação do sujeito (seu papel ativo no desenvolvimento).

O processo de compreensão de sentido-significado, conteúdo as ações de aprendizagem (base orientadora da ação-motivação) e seu papel na qualidade do desenvolvimento das ações mentais (pensamento, linguagem, atenção, etc.).

$\checkmark$ A internalização e sua interdependência com a externalização nos diferentes planos ou níveis de execução da ação, mesmo em suas transformações verbais.

A inclusão ativa do sujeito e dos significados nas ações e a generalização crítica de ambos nos vários níveis da fala, até o nível mental (fala interna); portanto, o valor da unidade significado-fala, 
uma vez que a ação por si só não pode provocar a generalização e outras características psicológicas do desenvolvimento.

$\checkmark$ A unidade da linguagem com o pensamento como processos principais dessa relação interfuncional, que confere certo conteúdo à atenção e à memória, neste caso, a memória histórica.

$\checkmark$ A interfuncionalidade das ações mentais, condicionando os diferentes modos de desenvolvimento e suas características psicológicas.

$\checkmark$ As funções da fala no domínio do próprio comportamento, cuja qualidade varia de acordo com o tipo de base orientadora da ação.

$\checkmark$ O papel do controle (atenção) na regulação desse comportamento.

$\checkmark$ As características psicológicas que mostram as transformações do sujeito no desenvolvimento.

$\checkmark$ A importância do nível de regulação da personalidade, além do nível de regulação do sujeito e de suas inter-relações históricas.

Ao refletir sobre essa teoria, apreciamos particularmente a análise específica de Galperin sobre a fala no processo de formação do plano mental, o que aprofunda a compreensão que Vygotski apresentou sobre esse problema em várias ocasiões, questão que poderia, de certa maneira, diferenciar Galperin do grupo dos kharkovistas (basicamente de Leontiev). É particularmente apreciável o papel dado por Galperin ao significado (conceito), ligado à mudança na forma de ação externa (material ou materializada) e interna (mental). Essa mudança qualitativa requer o código verbal em seus diferentes modos: externo para os outros ou diálogo, e para si mesmo ou reflexão. Ao mesmo tempo, a linguagem interna que dá permanência dinâmica à ideia, conceito, método etc. A fala (linguagem) no plano mental opera de maneira implícita, possibilitando, assim, a mediação entre ações ou processos mentais, interfuncionalidade. (VYGOTSKI, 2012).

Desde o surgimento da concepção histórico-culturalista, a Psicologia e a Pedagogia têm sido confrontadas com os hábitos de pensamento daqueles que estudam essa perspectiva teórico-metodológica com uma perspectiva positivistainstrumental. Os leitores do segundo tipo precisam enfrentar os colegas que não assumem facilmente - por qualquer motivo - uma abordagem de complexidade 
dialética que exija interdisciplinaridade, para que prevaleça sobre as tautologias psicológicas e pedagógicas (psicologismo e pedagogismo em conformidade) sobre o desenvolvimento da personalidade. Esse desenvolvimento não ocorre como uma sucessão linear na qual fragmentos são adicionados ou associados, graças a uma influência educacional síncrona com a aprendizagem. Segundo Vygotski, o desenvolvimento da personalidade é o problema central dessa Psicologia; neste caso, o desenvolvimento da personalidade nas condições de ensino. De um ensino que legitima as leis psicológicas no curso da aprendizagem-desenvolvimento, ou melhor, da zona de desenvolvimento próximo.

\section{N. F. Talízina: as ideias de confluências das teorias de} Galperin e de Leontiev aplicadas ao ensino

Ao se falar do sistema Galperin-Talízina, entendemos ser necessário explicitar as contribuições de Nina Fiódorovna Talízina (1923-2018) na estruturação do referido sistema. Destaque-se a grande oportunidade que representou a coincidência de Galperin dirigir a Cátedra de Psicologia das Idades ao mesmo tempo em que, durante um certo período, Talízina estava na direção da Cátedra de Pedagogia, ambas da Faculdade de Psicologia da Universidade Estadual de Moscou Mikhail Lomonosov. Esse fato histórico de alguma forma fortaleceu a introdução dessa teoria na prática. No entanto, não seria apropriado dizer que Talízina se dedicou mais à prática pedagógica do que à teoria, uma vez que também tinha uma perspectiva pessoal sobre a teoria proposta por Galperin, por exemplo, sobre a conceitualização da generalização e a base orientadora da ação. De fato, é notável o reconhecimento do trabalho de divulgação dessa autora, tanto do corpo teórico proposto por Galperin quanto de suas aplicações no desenho curricular, pedra angular de sua antecipada concepção teórica sobre a direção do ensino.

Formada pela Faculdade de Física e Matemática do Instituto Pedagógico Yaroslavl, Talízina realizou seus estudos de doutorado no Instituto de Pesquisa em Psicologia da Academia de Ciências Pedagógicas da URSS, sob a orientação do professor P. A. Shevarev, onde defendeu sua tese sobre o tema dos processos de resolução de problemas geométricos na escola. 
Desde 1950, trabalhou na Universidade Estadual de Moscou onde iniciou atividades de pesquisa sob a direção de Galperin. Colaborou com ele desde o início no desenvolvimento de sua teoria da formação das ações mentais e dos conceitos. Em 1970, sob supervisão de Galperin, Talízina realizou seus estudos de pós-doutorado no tema de gestão do processo de assimilação do conhecimento. (SOLOVIEVA; QUINTANAR, 2015).

Em 1963, assumiu o Departamento de Pedagogia da Faculdade de Filosofia da Universidade Estatal de Moscou e, após a criação do Departamento de Psicologia, acolheu o Departamento de Psicologia e Pedagogia Pedagógica, da qual ficou encarregada por 28 anos. A partir de 1966, ficou sob a sua responsabilidade o Laboratório de Psicologia Educacional e, desde 1989, o Centro de Formação de Pedagogos do Sistema Educacional da Faculdade de Psicologia da Universidade Estadual de Moscou, que oferece formação para professores e metodólogos com base na teoria da atividade da aprendizagem.

Talízina trabalhou na Universidade de Moscou com Leontiev, de quem recebeu uma grande influência e por quem tinha profunda admiração e respeito. Foi Leontiev quem a convidou para atividades científicas e administrativas na instituição. De fato, foi Galperin que lançou os fundamentos da Teoria da Atividade da Aprendizagem e, nos anos subsequentes, Talízina dedicou-se ao seu desenvolvimento. Os resultados foram utilizados para estudar os problemas da pedagogia e do psicodiagnóstico da inteligência. A cientista estabeleceu laços de amizade e profunda colaboração científica com Galperin, ao ponto de considerá-lo, ao lado de Leontiev, suas maiores inspirações e referências científicas.

Os estudos da teoria de Galperin realizados por Talízina, vinculados à Teoria da Atividade, representaram o sentido de suas pesquisas durante toda sua vida acadêmica. Talízina (2005) afirmou que, em todos seus anos de pesquisa, não mudou sua orientação teórica. Todos esses anos foram dedicados ao desenvolvimento de uma concepção de ensino e aprendizagem baseada nas ideias de Leontiev e Galperin. Realizou (inclusive com muitos pesquisadores, estudantes de graduação e graduados) muitas pesquisas. Esses trabalhos podem ser divididos em vários grupos: 1) teórica e experimental, dedicadas ao 
desenvolvimento de uma abordagem da atividade no campo da teoria psicológica da aprendizagem; 2) aplicada, destinadas a criar novas abordagens ao psicodiagnóstico da inteligência e novos fundamentos da didática. Todos esses estudos ajudaram a situar a teoria de Galperin no campo da Psicologia Pedagógica e a consolidação do Sistema Galperin-Talízina que se expressa, fortemente, no que se conhece pelo aprofundamento que Talízina.

\section{Sobre as contribuições de Talízina}

Gostaríamos de assinalar algumas contribuições de Talízina às ideias de Galperin, especificamente à sua Teoria da Formação das Ações Mentais e dos Conceitos, consideradas como uma configuração de um sistema didático, sem estabelecer hierarquia em relação à sua importância, deixando claro ser impossível abordar um número expressivo, dado o espaço restrito desta apresentação.

Um de seus trabalhos mais relevantes foi a aproximação da Teoria da Formação dos Conceitos e Ações Mentais de Galperin à Teoria da Atividade de Leontiev como um marco mais explícito ligado à questão da aprendizagem e do ensino dos estudantes no contexto escolar. Embora Galperin sofresse uma influência da teoria de Leontiev, como dizia Talízina (2007), ele mesmo reconheceu não ter elaborado uma Teoria da Atividade. Não obstante, como Talízina explica, Galperin criou um modelo da abordagem da atividade em Psicologia no qual se introduziu a ação como uma unidade de análise dos processos de estudo de forma diferenciada, pois os significados e sentidos são seu conteúdo, o que o guiou na busca e solução dos vários problemas e tarefas da vida, como apontamos anteriormente.

Talízina estudou os problemas fundamentais do desenvolvimento da psique e a natureza das diferenças individuais, bem como os problemas psicológicos e pedagógicos da formação de métodos de pensamento matemático. Ela expandiu significativamente as ideias de orientação da teoria de Galperin, assim como sua tipologia, ao mostrar as possibilidades não de três tipos, como acreditava Galperin, mas de oito tipos, o que resultou na compreensão da orientação do estudante no marco da sua zona de desenvolvimento próximo. É importante 
assinalar que, da forma como essa zona foi formulada por Vygotski, Galperin (2001), considerava que a sua utilização prática apresentava certa complexidade e dificuldade para sua implementação na pesquisa. Dessa forma, Talízina, como explicam Solovieva e Quintanar (2018), demonstrou, em pesquisas realizadas sob sua direção, uma aproximação importante do conceito de ZDP ao de base orientadora da ação, em especial nos processos de internalização que levam à formação das ações mentais e dos conceitos.

Por sua vez, Solovieva e Quintanar (2018) mostram uma outra contribuição importante de Talízina em relação às etapas de formação das ações mentais e dos conceitos, quando a pesquisadora diferencia as ações materiais e materializadas da ação perceptiva no caso de crianças da idade pré-escolar, o que tem um significado relevante para a aprendizagem dessas crianças.

Um outro ponto no qual Talízina (1993) realizou aportes às ideias de Galperin foi o da motivação como componente importante da atividade dos estudantes. Embora Galperin tenha levado em conta a motivação como algo essencial para a formação das ações mentais e dos conceitos, não desenvolveu esse aspecto de forma extensiva.

Seu ciclo de conferências em Cuba, nos anos 1980, sobre a Teoria da Direção do Ensino Universitário e do Desenho Curricular, publicado posteriormente pelo Centro de Estudos e Aperfeiçoamento do Ensino Superior da Universidade de Havana, foi memorável e de amplo conhecimento entre os professores dos departamentos universitários daquela década, e, no início dos anos 1990, especialmente, nas Ciências Naturais e Exatas como a Engenharia. Pode-se dizer que, além de ser uma pesquisadora incansável, Talízina era embaixadora dessas ideias no exterior, incluindo países da América Latina e do Caribe. Mais recentemente, contribuições desse tipo podem ser destacadas no México, onde desenvolveu diversas contribuições em universidades. Talízina foi laureada com diversos prêmios internacionais em reconhecimento à sua obra.

Cabe expressar a extensa e relevante contribuição de Talízina à Educação e à Psicologia, à formação de notáveis pesquisadores e psicólogos, à formação de 
professores e de outros profissionais de diversos países. Sua obra, relacionada a Galperin de forma indissociável, é referência de dimensão mundial.

Todos os aspectos apresentados mostram apenas parte das contribuições de Talízina à Psicologia, à Pedagogia e à Psicopedagogia, assim como refletem seu grande talento e atividade criativa multifacetada.

O Sistema Galperin-Talízina é uma forma de se explicar a natureza dialética dos processos de ensino-aprendizagem, nos quais a aprendizagem é concebida como um tipo específico de atividade orientadora, revelando um ponto de vista do significado do que é o aprender no contexto escolar e do papel do ensino na escola. Os pesquisadores entenderam e demonstraram experimentalmente a influência dos métodos de ensino, nesse processo, durante muitos anos de pesquisas segundo o princípio de Vygotski: ser o bom ensino potencializador do desenvolvimento dos estudantes.

Galperin e Talízina claramente deram continuidade às linhas de pensamento de Vygotski e Leontiev, não no sentido da operacionalização das ideias desses autores, mas na busca de uma explicação criativa para o papel dos meios culturais como ferramentas mediadoras nos processos de internalização, pelas quais o plano interno da atividade mental é formado na relação dialética com a atividade externa em situações socio-históricas de colaboração.

Diversas pesquisas que deram continuidade as ideias do Sistema GalperinTalízina mostram o caminho de novos direcionamentos e um aumento das possibilidades teóricas e práticas desse sistema num ensino comprometido com o desenvolvimento da personalidade dos estudantes.

As ideias do Sistema Galperin-Talízina estão presentes na atualidade em discussões da Psicologia pedagógica em diversos países de forma extensiva e significativa. Essa situação se evidencia em diversas publicações de eventos científicos e em revistas internacionais de grande influência nos campos da Psicologia e da Pedagogia.

Podemos afirmar que, embora haja todo um conjunto de críticas, necessárias aos processos das ciências, não se constata um silêncio das ideias de Galperin e Talízina na atualidade. Pelo contrário, se observa um crescente interesse por esses 
autores em países preocupados com diferentes alternativas teóricas que possam ajudar a compreender e desenvolver as aprendizagens e a educação dos estudantes.

O fio condutor do presente Dossiê mostra possibilidades de atualização do trabalho de Galperin e Talízina, manifestando uma maneira qualitativamente distinta de entender o vínculo teoria-metodologia-prática e aprendizagemdesenvolvimento, como eixos fundamentais de análise nas contribuições desses dois representantes da concepção histórico-culturalista.

Os artigos do Dossiê se iniciam com o texto intitulado: "Sobre o status científico e o significado de uma teoria psicológica”, do professor Andrei I. Podolskij, da Universidade Estadual de Moscou. Nesse artigo, o autor, que realizou seus estudos de doutorado com Galperin e é um dos pesquisadores mundialmente reconhecidos por dar continuidade às suas ideias desse importante psicólogo, apresenta uma análise central da teoria, suas potencialidades e aspectos susceptíveis à reflexão crítica para sua instrumentalização na prática do ensino no contexto escolar. Situa a teoria no seu contexto histórico, destacando momentos significativos de aplicação na antiga União Soviética, o seu interesse na Psicologia mundial, assim como aborda um período de reduzido interesse pela teoria devido a diversos fatores que discute no texto.

O artigo é esclarecedor no que diz respeito ao caráter de sistema da teoria, especificando o conteúdo de cada um dos três subsistemas: as condições relativas à orientação para a ação que sustenta a aprendizagem; os indicadores que caracterizam a qualidade da ação a ser formada e dirigem o processo de sua formação; as etapas da formação das ações mentais. Podolskij chama a atenção para a necessidade de uma aplicação bem-sucedida da teoria no contexto escolar, o que implica não na reprodução literal de ideias abstratas, mas num planejamento criativo no qual se considerem as ideias de Galperin nas condições psicológicas segundo o contexto de sua aplicação.

O segundo artigo: "Las acciones mentales y el problema de las etapas de su formación: siguiendo a Galperin y Talízina”, dos autores Yulia Solovieva e Luis Quintanar (pesquisadores que realizaram diversos estudos com Talízina) da Universidad Autónoma de Tlaxcala, México, discute as contribuições do Sistema Galperin-Talízina para a Psicologia do desenvolvimento no que diz respeito à formação de conceitos e de ações mentais em crianças no contexto escolar, com 
contribuições significativas para a discussão das ações materiais, materializadas e perceptíveis, diferenciando as ações práticas das intelectuais. Por sua vez, enfatiza o lugar das ações de orientação como objeto da atenção nos processos de internalização representados pelas etapas da teoria de Galperin.

$\mathrm{O}$ artigo revela um olhar crítico construtivo para o debate atual da teoria, mostrando as potencialidades das contribuições propostas por Galperin e Talízina nos estudos das conexões entre aprendizagem e desenvolvimento em intervenções pedagógicas em crianças após diagnósticos neurológicos para, dessa maneira, inserir a discussão da aplicação do Sistema Galperin-Talízina no campo da Neuropsicologia, o que se configura como uma inovação na aplicação das ideias do referido sistema teórico-didático.

A autora Gloria Fariñas León, pesquisadora da teoria de Galperin, que realizou seus estudos de doutorado na Universidade de Moscou sob a orientação de Galperin, e atualmente é professora da Universidade de La Salle del Bajío, México, é a autora do terceiro dos artigos, intitulado: "La autonomía como indicador del desarrollo de la personalidad: los aportes de P. Ya. Galperin”. No artigo, a pesquisadora discute a autonomia do estudante como um indicador qualitativo central do desenvolvimento da personalidade que resulta da influência da aprendizagem sobre o desenvolvimento potencial. Com base nas contribuições da teoria de Galperin sobre a formação das ações mentais e dos conceitos, a autora discute a formação da autonomia não como algo isolado, mas como resultado de dinâmicas interfuncionais de processos psicológicos e das mudanças que se produzem sob a mediação das influências do ensino referenciado na teoria de forma dialética e complexa. A autora faz uma nova leitura ao situar a autonomia como um indicador sob seu ponto de vista, o que lhe confere uma atualização e ressignificação criativa de um elemento essencial na teoria de Galperin. O artigo apresenta possibilidades para uma organização do currículo escolar baseada nos postulados discutidos e na natureza integral das funções psicológicas e, consequentemente, dos processos de sua formação, o que permite o desenvolvimento da autonomia dos estudantes como resultado de uma aprendizagem comprometida com o desenvolvimento da sua personalidade. 
Os autores Isauro Beltrán Núñez (que realizou estudos na Universidade de Moscou sob a supervisão de Talízina, Reshetova e Salmina), Betânia Leite Ramalho e Marcus Vinicius de Faria Oliveira são os autores do quarto artigo do dossiê,-que se intitula: "A teoria de Galperin e a formação de conceitos teóricos na educação em ciências: reflexões críticas e possibilidades”. Se trata de uma discussão da formação de conceitos teóricos segundo a teoria que refuta as críticas feitas à teoria nesse processo. Os autores assumem que os conceitos teóricos das disciplinas científicas, possíveis de definição segundo a lógica dialética, são os que têm maior potencial para o desenvolvimento do pensamento científico dos estudantes, assim como é a orientação do terceiro tipo, na qual se incluem, o mecanismo psicológico de sua formação.

Ao defender o caráter sistêmico, complexo e dialético da teoria, que integra três subsistemas, os autores rebatem outras críticas feitas às ideias de Galperin, que levam ao mal entendimento de algumas dessas ideias e que são resultado, dentre outros, das leituras fragmentadas e descontextualizadas de publicações de Galperin, assim como de uma diversidade de interpretações, nem sempre coerentes com as ideias centrais da teoria. Os autores procuram esclarecer essa situação no caso da educação em Ciências na escola básica, mostrando a necessidade de se considerar a teoria e mostrar o conceito teórico do subsistema das condições necessárias para a orientação do terceiro tipo, do subsistema dos indicadores qualitativos da orientação desejada e das etapas pelas quais se organiza o processo para a formação da orientação e, consequentemente, do conceito teórico.

Os autores pretendem apresentar uma interpretação da teoria no processo de formação desses conceitos, considerando aspectos por vezes desconsiderados e que podem contribuir com o debate de aspectos teóricos e metodológicos em pesquisas e atividades de ensino na educação em Ciências.

No quinto artigo, dos autores cubanos Miguel Angel Toledo Méndez e Isaac Iran Cabrera Ruiz discutem uma aplicação inovadora da teoria de Galperin na área da formação na Medicina, quando vinculam esse referencial à formação para a atuação na atenção médica integral, como atividade geral e estruturante da formação desse profissional, no contexto da disciplina de Psicologia. Baseado nas 
ideias de Galperin, o programa proposto para essa disciplina se estrutura vinculando as habilidades gerais (como expressões de invariantes) ao modelo profissional e, dessa forma, definem os esquemas das bases orientadoras dessas ações como modelos gerais do pensamento do profissional. A estruturação dos conteúdos em termos de invariantes é adequada às exigências da base orientadora da ação do terceiro tipo, fundamental para um ensino que se organiza considerando a relação dialética do abstrato para o concreto, do geral para o singular, e a gênese (essência) que se desenvolve de forma dialética e que contribui para o pensamento teórico dos estudantes.

No texto, se apresentam os elementos teóricos e metodológicos que fundamentaram estudos empíricos orientados para a formação dessas habilidades, desenvolvidos durante quatro anos com estudantes de cursos de medicina em Cuba.

O sexto artigo, das autoras Severina Andréa Dantas de Farias e Rogéria Gaudencio de Rêgo, sob o título: "Assimilação de conceitos na Matemática: uma possibilidade metodológica aplicada ao ensino a distância” faz uma discussão da aplicação das ideias do Sistema Galperin-Talízina, com foco na Teoria da Aproximação da Atividade, no estudo dos conteúdos de triângulos em Geometria, combinada com a metodologia de resolução de problemas. A experiência formativa desenvolvida num curso de licenciatura em Matemática, na modalidade a distância, no período de oito meses revela as possibilidades do referencial adotado na aprendizagem dos futuros professores. Foi constatado o desenvolvimento de um maior autocontrole, maior autonomia e melhor organização lógica do pensamento matemático influenciados pelo domínio de uma base orientadora que permitiu a solução de problemas com sucesso no referido domínio. As autoras concluem que a Teoria da Aproximação da Atividade de Talízina exerce uma influência positiva quando aliada à resolução de problemas nos processos de formação dos professores de Matemática, sendo a experiência, por sua vez, uma forma de aproximação dos licenciandos a um conhecimento importante para pensar suas futuras práticas no ensino da matemática dos estudantes da educação básica. 
No sétimo artigo os autores Héctor José García Mendoza e Oscar Tintorer Delgado da UFRR apresentam o artigo intitulado: "Proposta de um "esquema da base orientadora completa da ação da atividade de situações problema discente”, no qual discutem o potencial do esquema da base orientadora da ação (EBOCA) como um recurso para a interação entre professor, estudante e tarefa com caráter problematizador. Segundo Majmutov, a atividade de situações-problema discente deve transitar pelas diferentes etapas de formação das ações mentais e dos conceitos de Galperin, mediada pela estratégia metodológica de direção da atividade de estudo de Talízina. Sendo assim, o propósito do texto é apresentar um EBOCA como modelo didático de referência para a orientação, execução e controle da atividade de situações-problema discente. Os autores adequam a proposta na resolução do problema por meio de modelo matemático e experimentação. O texto representa uma importante contribuição à discussão do lugar das invariantes do conhecimento e das ações no processo de organização do ensino, considerando a natureza da aprendizagem que se deriva do terceiro tipo de orientação na teoria de Galperin.

No Dossiê se inclui a tradução do artigo de N. F. Talízina intitulado: "Os princípios da Psicologia soviética e os problemas do psicodiagnóstico da atividade cognitiva”, publicado na Antología de la psicología pedagógica y de las edades (C. Habana, Editorial Pueblo y Educación, 1986) e, inicialmente, publicado na Coleção Probliemi programirovannovo obuchenia organizada por N. F. Talízina (Moscou, 1979). Embora a data de publicação inicial do artigo se conservem ideias e postulados essenciais para as discussões atuais do diagnóstico do desenvolvimento intelectual dos estudantes que tomam como fundamento a teoria de P. Ya. Galperin. A autora discute a importância do conhecimento do sistema estrutural e funcional da atividade como modelo do conteúdo que garante a solução das tarefas, assim como os diferentes níveis desejados da sua formação para caracterizar as aprendizagens (nível real de desenvolvimento) zona de desenvolvimento próximo dos estudantes. Por sua vez, exemplifica as potencialidades desse tipo de diagnóstico se comparado com os tradicionais, de base behaviorista e piagetiana, mostrando seu potencial em pesquisas preocupadas com a aprendizagem como 
processo e não apenas como produto de determinadas atividades dirigidas ao desenvolvimento intelectual dos estudantes.

No Dossiê, também se apresenta o resumo da tese desenvolvida por Alessandro Augusto de Barros Façanha no Programa de Educação do Centro de Educação, Universidade Federal do Rio Grande do Norte, no ano de 2019, intitulada "A orientação da ação para leitura crítica a partir de uma experiência formativa: uma contribuição para o ensino de química". A pesquisa, realizada com estudantes de um curso de licenciatura em Química, teve como finalidade estudar a influência de uma experiência formativa baseada na teoria de Galperin na compreensão desses futuros professores sobre a ação de ler de forma crítica textos de Química no contexto da educação científica na educação básica. Para essa finalidade, diagnosticou o conteúdo da ação de orientação da referida ação dos estudantes, comparando com uma orientação do tipo III. A partir desses resultados, a experiência formativa possibilitou, seguindo as etapas de motivação e elaboração da base orientadora da teoria de Galperin, uma nova orientação geral com maior grau de generalização para ler textos de forma crítica como via da aprendizagem de conteúdos na disciplina. Os resultados empíricos na etapa materializada, na qual se utilizou a orientação geral na forma de esquemas (EBOCAS), revelaram uma melhor compreensão para orientação e leitura de forma consciente, o que se traduziu numa melhor qualidade dessa atividade.

\section{Referências}

FARIÑAS, G. Acerca del pensamiento histórico culturalista desde la perspectiva de los psicólogos y pedagogos cubanos. Em: Alternativas cubanas em Psicología. v. 3, 2015, p. 8-17.

FARIÑAS, G. Aprendizaje y desarrollo desde la perspectiva de la complejidad. La Habana: Ed. Félix Varela, 2017.

FARIÑAS, G. Aprendizaje y desarrollo desde la perspectiva de la complejidad: la teoría em la práctica. La Habana: Ed. Félix Varela, 2019.

GALPERIN, P. YA. Seis conferencias de psicología. La Habana: Impresiones ligeras de la Universidad de La Habana, 1972. 
GALPERIN, P. YA. Introducción a la psicología, un enfoque dialéctico. Madrid: Ed. Pablo del Río. 1979.

GALPERIN, P. Ya Sobre la formación de los conceptos y de las acciones mentales. In: ROJAS, L. Q. La formación de las funciones psicológicas durante el desarrollo del niño. Tlaxcala: Editora Universidad Autónoma de Tlaxcala, 2001a. p. 27-40.

LEONTIEV, A. N. Actividad, Consciencia, Personalidad. La Habana: Editorial Pueblo y Educación, 1992.

LEONTIEV, D. A. Aproximación a la teoría de la actividad: Vygotski en el presente. Eclecta. v. III, n. 9-10, julio-diciembre. 2005. p.29-39.

LONGAREZI, A. M. PUENTES. R. V. (Orgs.). Ensino Desenvolvimental II: vida, pensamento e obra dos principais representantes russos. Uberlândia: Edufu, 2015. p. 283-314. https://doi.org/10.14393/edufu-978-85-7078-464-3

NÚÑEZ, I. B. Vygotsky, Leontiev, Galperin. Formação de Conceitos e princípios Didáticos. Brasília: Liber Livro, 2009.

NÚÑEZ, I. B.; OLIVEIRA, M. V. de F. P. Ya. Galperin: vida e obra do criador da teoria da formação por etapas das ações mentais e dos conceitos. In: LONGAREZI, Andréa Maturano. PUENTES, Roberto Valdés (Orgs.). Ensino Desenvolvimental II: vida, pensamento e obra dos principais representantes russos. Uberlândia: Edufu, 2015. p. 263-390. https://doi.org/10.14393/edufu-978$\underline{\text { 85-7078-464-3 }}$

NÚÑEZ, I. B.; RAMALHO, B. L; Oliveira, M. V. F. A formação de habilidades gerais no contexto escolar: contribuições da teoria de P. Ya. Galperin. In: NÚÑEZ, I. B.; RAMALHO, B. L. (orgs.). Galperin y la teoría de la formación planeada por etapas de las acciones mentales y de los conceptos. Intestigaciones y las experiencias para una enseñanza innovadora. Campinas: Mercado de Letras, 2018. p. 23-78.

SOLOVIEVA, Yu.; QUINTANAR, L. Teoría de Galperin: Orientación para psicología y neuropsicología. In: NÚÑEZ, I. B.; RAMALHO, B. L. (orgs.). Galperin y la teoría de la formación planeada por etapas de las acciones mentales y de los conceptos. Investigaciones y las experiencias para una enseñanza innovadora. Campinas: Mercado de Letras, 2018. p. 101-132.

SOLOVIEVA, Yu.; QUINTANAR, L. Aportaciones de N. F. Talizina para la psicología y el desarrollo de la educación. In: LONGAREZI, A. M.. P.: VALDÉS, R. (Orgs.). Ensino Desenvolvimental II: vida, pensamento e obra dos principais representantes russos. Uberlândia: Edufu, 2015. p. 263-390.

https://doi.org/10.14393/edufu-978-85-7078-464-3 
STEPNOVA. M. A. Psicólogo, médico, filósofo: marcos de uma biografia científica de P. Ya. Galperin. revista nacional de psicologia. n. 3. v. 27. p. 21-32, 2017.

SEMENOV I.N. Personological reflection of creative life of N.F. Talyzina and her psychological and educational activities at the Department of Pedagogy of the Moscow State University (on the 90th anniversary of the RAS academician, MSU professor Talyzina N.F.). Psychology. Historical-critical Reviews and Current Researches. 1-2, p. 63-93, 2014. (em russo).

TALÍZINA, N. F. Essência da Abordagem de Atividade em Psicologia.

Metodologia e história da psicologia. 2007. v. 2. Ed.4, p. 157-162. (em russo).

TALÍZINA, N. F. Memórias, pensamentos, conversas. "Estou certo de que o futuro da psicologia está na abordagem da atividade". Revista Psicológica. v. 26, n. 4, 2005. p. 105- 113. (em russo).

TALÍZINA, N. F. La teoría de la actividad aplicada a la enseñanza. México: Universidad Autónoma de Puebla, 2019.

TALÍZINA, N. F. Teoria da formação planejada de ações mentais hoje. Questões de Psicologia. v. 2. No. 1. p. 92-101. 1993.

TALÍZINA, N. F. Essência da abordagem de atividade em psicologia. Metodologia e História da Psicologia. v 2. Ed. 4, p. 157- 162, 2007.

TALÍZINA, N. F. Memórias, pensamentos, conversas. "Estou certo de que o futuro da psicologia está na abordagem da atividade" Entrevista conduzida por V.I. Artamonov (fevereiro de 2005). Revista Psicológica. v. 26, n. 4, 2005 p. 105113.

ZINCHENKO, YU, P. et al. (Orgs.). Teoria de atividade do ensino: estado atual e perspectiva. Materiais da Conferência Científica Internacional, Moscou, 6 a 8 de fevereiro de 2014. Moscou: Editora da Universidade Estadual de Moscou, 2014. (em russo). 